\title{
Shell Thickness-Dependent Strain Distributions of Confined Au/Ag and Ag/Au Core-Shell Nanoparticles
}

\author{
Feng Liu, ${ }^{1}$ Honghua Huang, ${ }^{2}$ Ying Zhang, ${ }^{2}$ Ting Yu, ${ }^{2}$ Cailei Yuan, ${ }^{2}$ and Shuangli Ye \\ ${ }^{1}$ Institute of Microelectronics and Information Technology, Wuhan University, Wuhan, Hubei 430072, China \\ ${ }^{2}$ Laboratory of Nanomaterials and Sensors, School of Physics, Electronics and Communication, Jiangxi Normal University, \\ Nanchang, Jiangxi 330022, China \\ ${ }^{3}$ School of Printing and Packaging, Wuhan University, Wuhan, Hubei 430072, China
}

Correspondence should be addressed to Shuangli Ye; slye@whu.edu.cn

Received 27 November 2014; Accepted 31 December 2014

Academic Editor: Wen Lei

Copyright (C) 2015 Feng Liu et al. This is an open access article distributed under the Creative Commons Attribution License, which permits unrestricted use, distribution, and reproduction in any medium, provided the original work is properly cited.

\begin{abstract}
The shell thickness-dependent strain distributions of the $\mathrm{Au} / \mathrm{Ag}$ and $\mathrm{Ag} / \mathrm{Au}$ core-shell nanoparticles embedded in $\mathrm{Al}_{2} \mathrm{O}_{3}$ matrix have been investigated by finite element method (FEM) calculations, respectively. The simulation results clearly indicate that there is a substantial strain applied on both the $\mathrm{Au} / \mathrm{Ag}$ and $\mathrm{Ag} / \mathrm{Au}$ core-shell nanoparticles by the $\mathrm{Al}_{2} \mathrm{O}_{3}$ matrix. For the $\mathrm{Au} / \mathrm{Ag}$ nanoparticles, it can be found that the compressive strain existing in the shell is stronger than that on the center of core and reaches the maximum at the interface between the shell and core. In contrast, for the Ag/Au nanoparticles, the compressive strain applied on the core is much stronger than that at the interface and that in the shell. With the shell thickness increasing, both of the strains in the $\mathrm{Au} / \mathrm{Ag}$ and $\mathrm{Ag} / \mathrm{Au}$ nanoparticles increase as well. However, the strain gradient in the shell decreases gradually with the increasing of the shell thickness for both of $\mathrm{Ag} / \mathrm{Au}$ ad $\mathrm{Au} / \mathrm{Ag}$ nanoparticles. These results provide an effective method to manipulate the strain distributions of the $\mathrm{Au} / \mathrm{Ag}$ and $\mathrm{Ag} / \mathrm{Au}$ nanoparticles by tuning the thickness of the shell, which can further have significant influences on the microstructures and physical properties of $\mathrm{Au} / \mathrm{Ag}$ and $\mathrm{Ag} / \mathrm{Au}$ nanoparticles.
\end{abstract}

\section{Introduction}

Nanoparticles with core-shell structure have attracted intensive scientific and technical interests due to their potential applications in catalysis, drug delivery, microelectronics, sensor, and many other emerging nanotechnologies [1-5]. Particularly, the bimetallic nanoparticles with core-shell structure have constantly been the subject of these studies because of their improved electronic, optical, and catalytic performances compared with those of monometallic nanoparticles $[6,7]$. Moreover, it has been demonstrated that the composition, size, shape, and surface modification of these bimetallic nanoparticles can be tailed for the targeted applications [8,9]. Among them, $\mathrm{Au} / \mathrm{Ag}$ and $\mathrm{Ag} / \mathrm{Au}$ core-shell nanoparticles have currently captured exponential attention due to their unique optical and photonic properties. It has been illustrated that $\mathrm{Au}$ and $\mathrm{Ag}$ present a broad absorption band in the visible region of the electromagnetic spectrum [10-12], which can be due to the collective oscillation of the free conduction electrons induced by an interacting electromagnetic field [13]. Moreover, $\mathrm{Au}$ is a suitable candidate for biomedical applications because of its excellent performances on biocompatibility, chemical stability and easy surface modification, and so forth. Therefore, the $\mathrm{Au} / \mathrm{Ag}$ and $\mathrm{Ag} / \mathrm{Au}$ core-shell nanoparticles with surface plasmon enhancement and high levels of sensitivity have tremendous applications for optical, chemical, and bimolecular devices. For example, the generation of detectable Fano-resonance has been demonstrated in $\mathrm{Au} / \mathrm{Ag}$ core-shell structure [14], which has a great potential in the subwavelength waveguides, and low-loss metamaterials sensors [15-18].

On the other hand, strain engineering provides a general strategy to control the morphology and microstructure of the nanostructures, leading to an enhancement of their device 


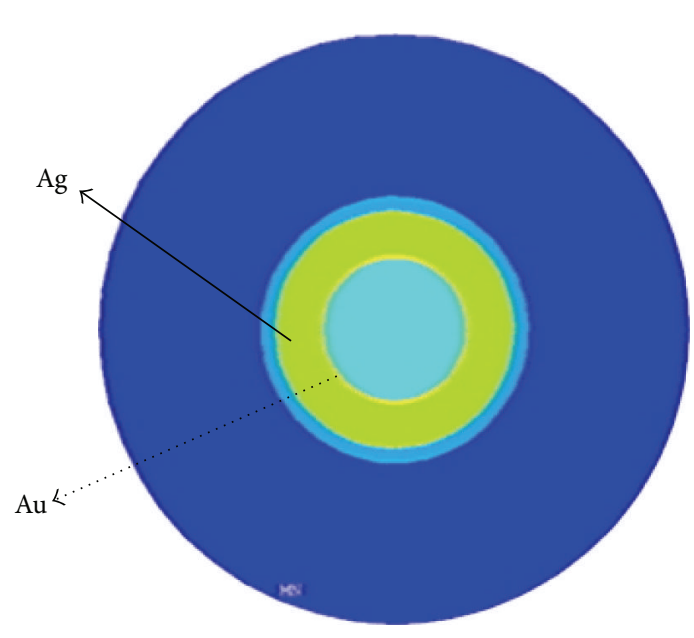

(a)

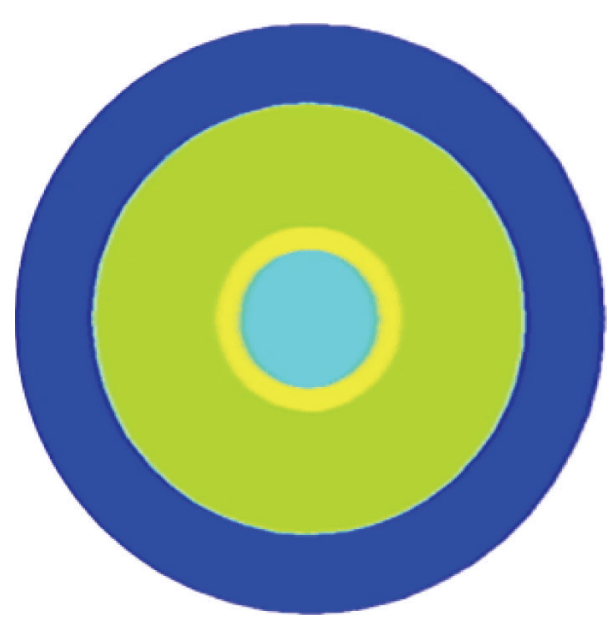

(c)

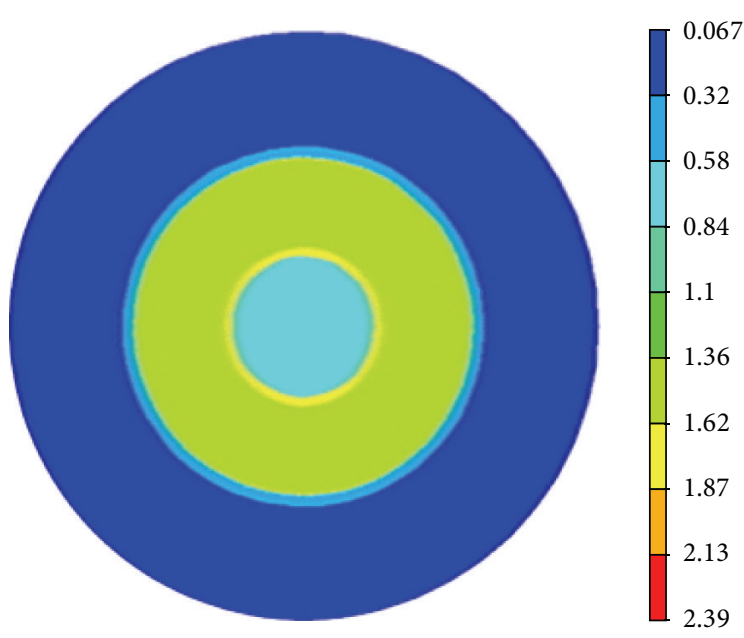

(b)

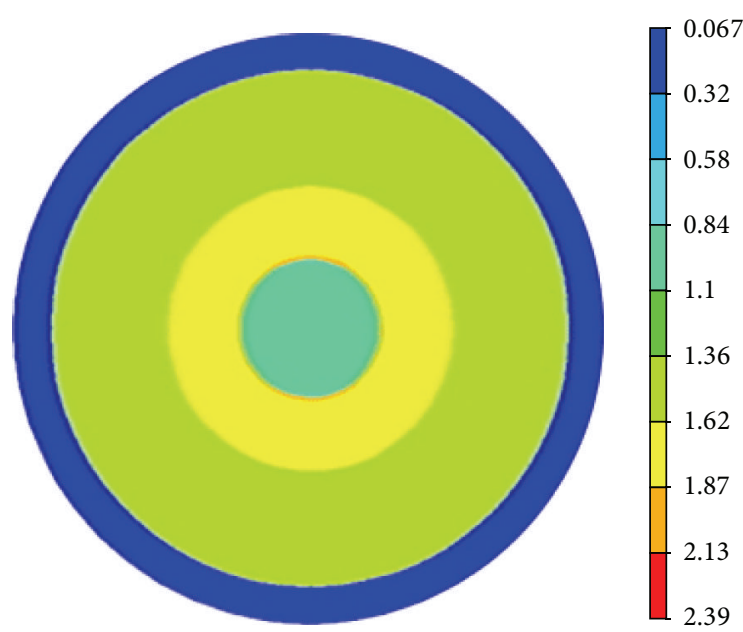

(d)

FIGURE 1: Morphological cross-sectional strain distribution of embedded core-shell Au/Ag nanoparticles with the shell thickness of (a) $2.5 \mathrm{~nm}$, (b) $5 \mathrm{~nm}$, (c) $7.5 \mathrm{~nm}$, and (d) $10 \mathrm{~nm}$, respectively.

performance. For example, quantum dots, a kind of nanostructures for making high performance nanodevices, can be realized by using self-assembled growth technique, which is based on a process of strain accumulation and relaxation in the system $[19,20]$. For the core-shell nanoparticles confined in a host matrix, a substantial strain is induced [21-25], which can be used to tune the interplay between the core and shell layers, the morphology [26, 27], and optical properties [28]. Therefore, for the $\mathrm{Au} / \mathrm{Ag}$ and $\mathrm{Ag} / \mathrm{Au}$ core-shell nanoparticles, along with the enhanced light absorption, spectral tuning of the surface plasmon resonance by strain can provide another dimension besides the usual size and composition manipulation. Here, the shell thickness-dependent strain distributions of the $\mathrm{Au} / \mathrm{Ag}$ and $\mathrm{Ag} / \mathrm{Au}$ core-shell nanoparticles embedded in $\mathrm{Al}_{2} \mathrm{O}_{3}$ matrix have been investigated, respectively. The simulation results offer an effective method to manipulate the strain distributions of the $\mathrm{Au} / \mathrm{Ag}$ and $\mathrm{Ag} / \mathrm{Au}$ nanoparticles by tuning the thickness of the shell, which can further have significant influences on the surface states and surface plasmon resonance of $\mathrm{Au} / \mathrm{Ag}$ and $\mathrm{Ag} / \mathrm{Au}$ nanoparticles.

\section{Methods}

In this paper, a FE calculation is performed to simulate the strain distribution of embedded $\mathrm{Au} / \mathrm{Ag}$ and $\mathrm{Ag} / \mathrm{Au}$ core/shell nanoparticles with different shell thickness. The interplay between the strain and the structure of confined $\mathrm{Au} / \mathrm{Ag}$ and $\mathrm{Ag} / \mathrm{Au}$ nanoparticles has been investigated. FE calculation has been applied successfully to continuum modeling of deformation [29] of materials. Recently, simulation on the strain distribution of nanoparticles by FE method has been widely studied $[30,31]$. For materials at nanoscale, the simulations by the continuum elastic FE method and the atomistic strain calculations have reached a general qualitative agreement $[32,33]$. Many physical properties of nanomaterials, including elastic anisotropy, thermal expansion, and threedimensional morphology, can be understood well by the FE simulation results. In our simulation, the FE model for the strain distribution is based upon the following assumptions. A spherical, linear-elastic core-shell $\mathrm{Au} / \mathrm{Ag}$ or $\mathrm{Ag} / \mathrm{Au}$ nanoparticle is confined in an isotropic and linear-elastic 


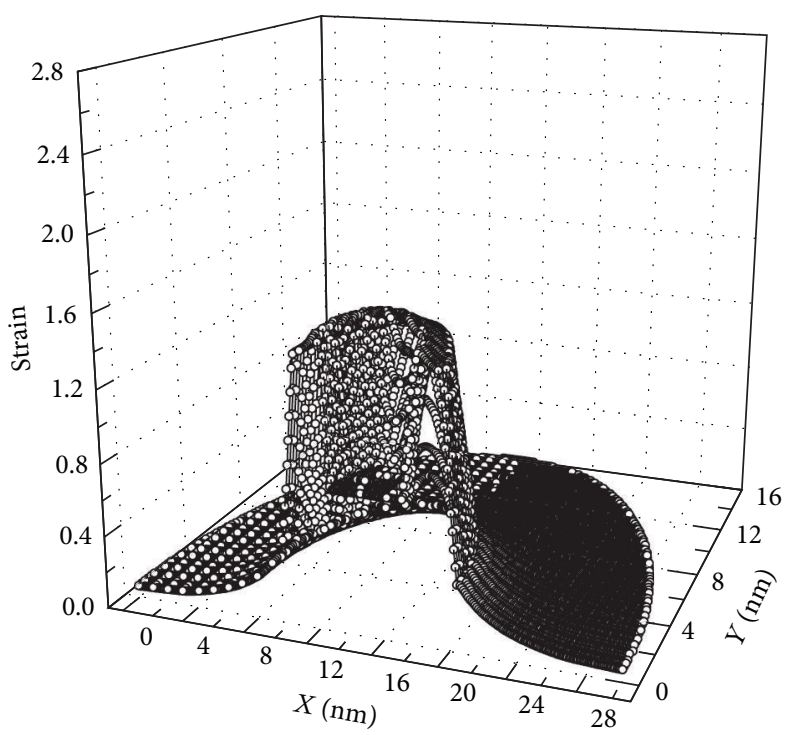

(a)

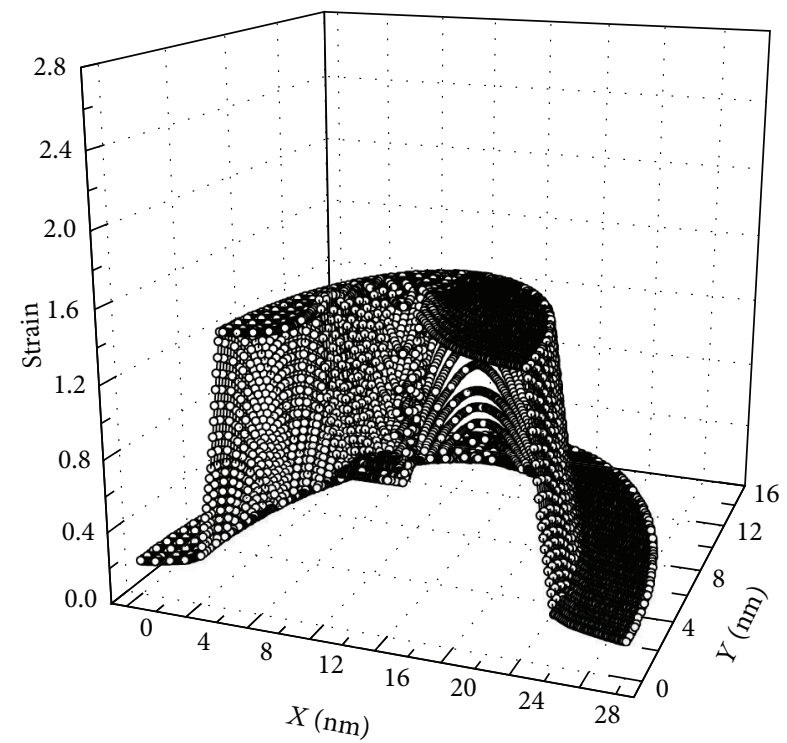

(c)

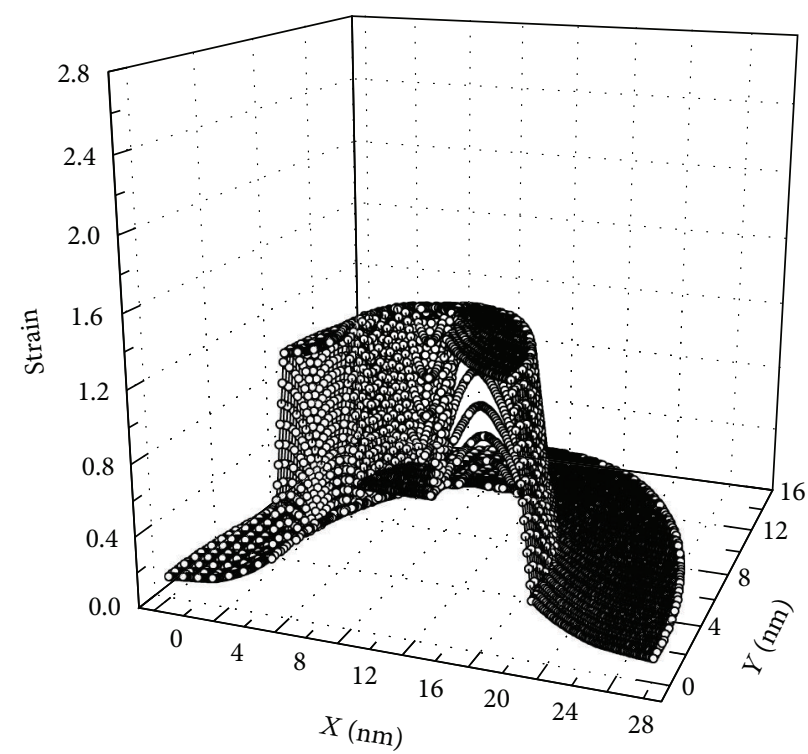

(b)

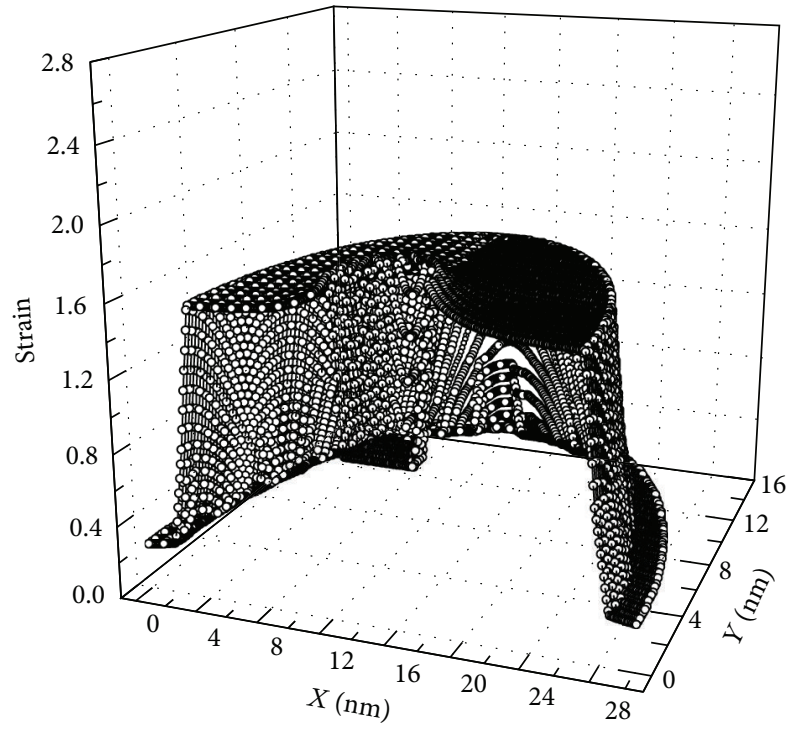

(d)

Figure 2: $X-Y$ plane strain profiles for Au/Ag nanoparticles with the shell thickness of (a) $2.5 \mathrm{~nm}$, (b) $5 \mathrm{~nm}$, (c) $7.5 \mathrm{~nm}$, and (d) $10 \mathrm{~nm}$, respectively.

matrix. The Au/Ag or Ag/Au nanoparticle surface is welded to the $\mathrm{Al}_{2} \mathrm{O}_{3}$ matrix. The core size is $2.5 \mathrm{~nm}$ and the shell thickness is $2.5 \mathrm{~nm}, 5 \mathrm{~nm}, 7.5 \mathrm{~nm}$, and $10 \mathrm{~nm}$ for each nanoparticle, respectively. The thermal expansion mismatch between the nanoparticles and $\mathrm{Al}_{2} \mathrm{O}_{3}$ matrix leads to a substantial strain in the confined $\mathrm{Au} / \mathrm{Ag}$ or $\mathrm{Ag} / \mathrm{Au}$ nanoparticles. Young's modulus is taken to be $170 \mathrm{GPa}, 76 \mathrm{GPa}$, and $360 \mathrm{GPa}$ for $\mathrm{Au}$, $\mathrm{Ag}$, and $\mathrm{Al}_{2} \mathrm{O}_{3}$, while Poisson's ratio is taken to be $0.42,0.38$, and 0.24 for $\mathrm{Au}, \mathrm{Ag}$, and $\mathrm{Al}_{2} \mathrm{O}_{3}$, respectively.

\section{Results and Discussion}

The morphological cross-sectional strain distributions for the core-shell $\mathrm{Au} / \mathrm{Ag}$ nanoparticles embedded in $\mathrm{Al}_{2} \mathrm{O}_{3}$ thin film with the shell thickness of $2.5 \mathrm{~nm}, 5 \mathrm{~nm}, 7.5 \mathrm{~nm}$, and $10 \mathrm{~nm}$ are presented in Figures 1(a)-1(d), respectively. It can be found that the strain distributes inhomogeneously, which can be tuned by the shell thickness. Correspondingly, the $X-Y$ plane strain profiles for embedded $\mathrm{Au} / \mathrm{Ag}$ nanoparticle with the shell thickness of $2.5 \mathrm{~nm}, 5 \mathrm{~nm}, 7.5 \mathrm{~nm}$, and $10 \mathrm{~nm}$ are shown in Figures 2(a)-2(d), respectively. Figures 2(a)-2(d) illustrate quantitatively that there is a large compressive strain applied on the $\mathrm{Au} / \mathrm{Ag}$ nanoparticle by the $\mathrm{Al}_{2} \mathrm{O}_{3}$ matrix. The strain is weaker in the core than that in the shell. It reaches the maximum at the interface and decreases with the layer away from the interface. With the shell thickness increasing, it can be seen that the strain existing in the core-shell Au/Ag nanoparticles becomes stronger. The strain distribution in 


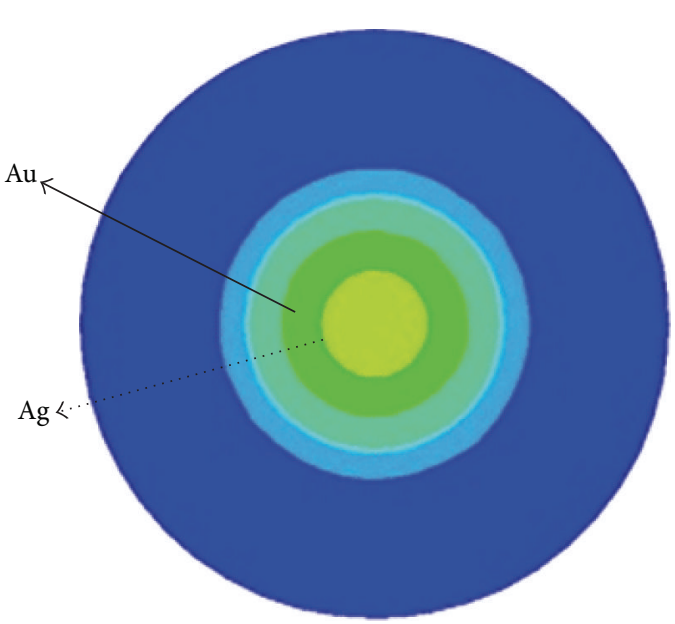

(a)

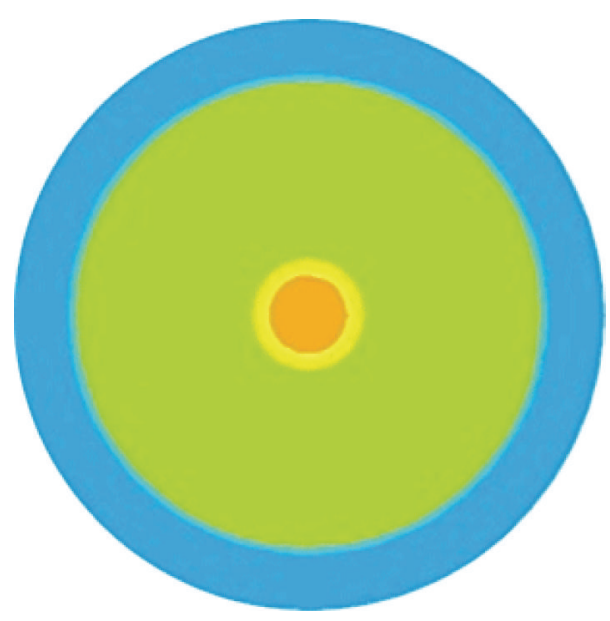

(c)
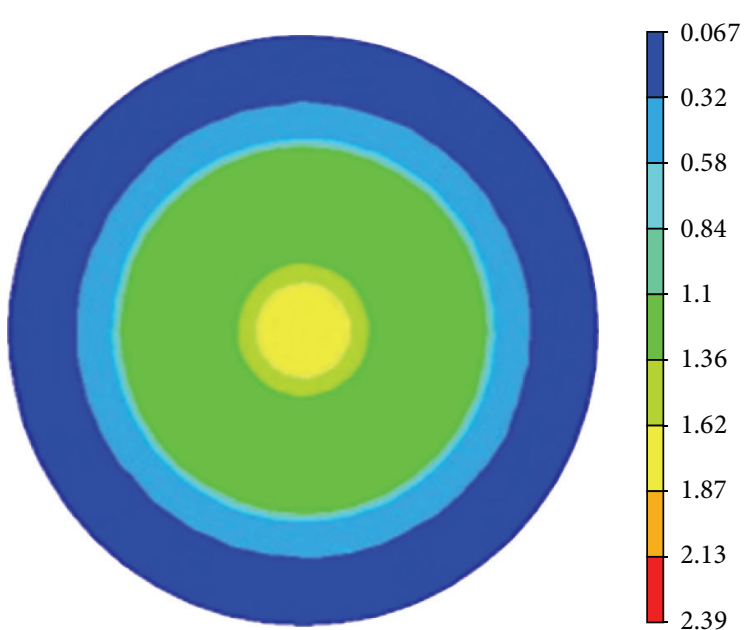

(b)

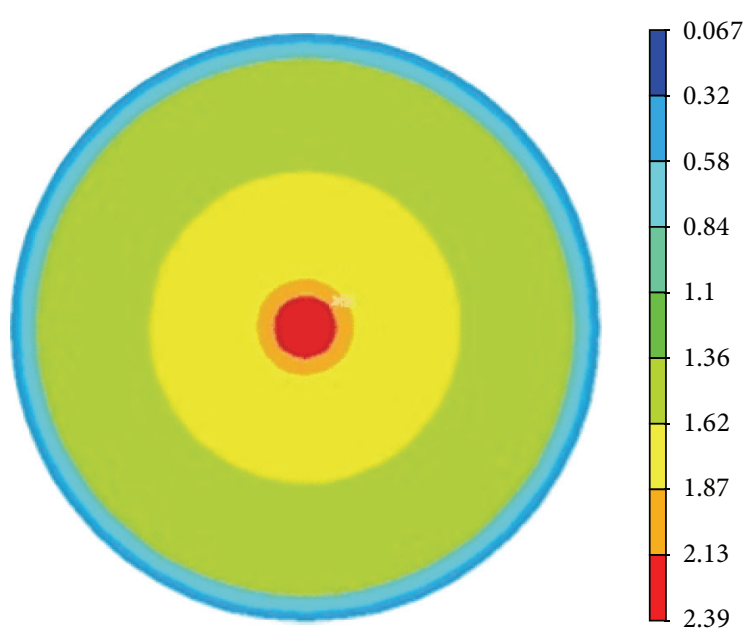

(d)

FIGURE 3: Morphological cross-sectional strain distribution of confined Ag/Au nanoparticles with the shell thickness of (a) $2.5 \mathrm{~nm}$, (b) $5 \mathrm{~nm}$, (c) $7.5 \mathrm{~nm}$, and (d) $10 \mathrm{~nm}$, respectively.

the core keeps homogenous. However, the inhomogeneousity of strain distribution existing in the shell is enhanced.

Similarly, the morphological cross-sectional strain distributions for $\mathrm{Ag} / \mathrm{Au}$ nanoparticles embedded in $\mathrm{Al}_{2} \mathrm{O}_{3}$ thin films with the shell thickness of $2.5 \mathrm{~nm}, 5 \mathrm{~nm}, 7.5 \mathrm{~nm}$, and $10 \mathrm{~nm}$ are presented in Figures 3(a)-3(d), respectively. The $X-Y$ plane strain profiles for embedded $\mathrm{Ag} / \mathrm{Au}$ nanoparticle with the shell thickness of $2.5 \mathrm{~nm}, 5 \mathrm{~nm}, 7.5 \mathrm{~nm}$, and $10 \mathrm{~nm}$ are illustrated in Figures 4(a)-4(d), respectively. It also can be seen that there is a compressive strain applied on the $\mathrm{Ag} / \mathrm{Au}$ nanoparticles by the $\mathrm{Al}_{2} \mathrm{O}_{3}$ matrix. However, the strain distributes quite differently from that in the $\mathrm{Au} / \mathrm{Ag}$ nanoparticle, which reaches the maximum in the core and decreases monotonously from the core to the shell in the $\mathrm{Ag} / \mathrm{Au}$ nanoparticles. With the shell thickness increasing, the strain increases as well. The strain distribution in the core keeps homogenous, and the inhomogeneousity of strain distribution existing in the shell is enhanced.
For a comparison, Figure 5 illustrates the strain distributions and the strain gradient for the $\mathrm{Au} / \mathrm{Ag}$ and $\mathrm{Ag} / \mathrm{Au}$ nanoparticles with the shell thickness of $2.5 \mathrm{~nm}, 5 \mathrm{~nm}, 7.5 \mathrm{~nm}$, and $10 \mathrm{~nm}$, respectively. It can be found that, for both of $\mathrm{Au} / \mathrm{Ag}$ and $\mathrm{Ag} / \mathrm{Au}$ nanoparticles, the strain is enhanced with the increasing of the shell thickness. Moreover, the strain increases faster for $\mathrm{Ag} / \mathrm{Au}$ than that for $\mathrm{Au} / \mathrm{Ag}$ nanoparticles. For these two core-shell nanoparticles with the same shell thickness, the strain on the core is larger for $\mathrm{Ag} / \mathrm{Au}$ than that for $\mathrm{Au} / \mathrm{Ag}$ nanoparticles, which can be due to the larger Young's modulus of Au than that of Ag. The strain gradient in the shell decreases gradually with the increasing of the shell thickness for both of $\mathrm{Ag} / \mathrm{Au}$ ad $\mathrm{Au} / \mathrm{Ag}$ nanoparticles. However, the strain gradient in the shell decreases faster for $\mathrm{Au} / \mathrm{Ag}$ than that for $\mathrm{Ag} / \mathrm{Au}$ nanoparticles. The homogeneous strain distribution in the core and the inhomogeneous strain in the shell can have a significant influence on the microstructure and morphology of $\mathrm{Au} / \mathrm{Ag}$ and $\mathrm{Ag} / \mathrm{Au}$ nanoparticles, which 


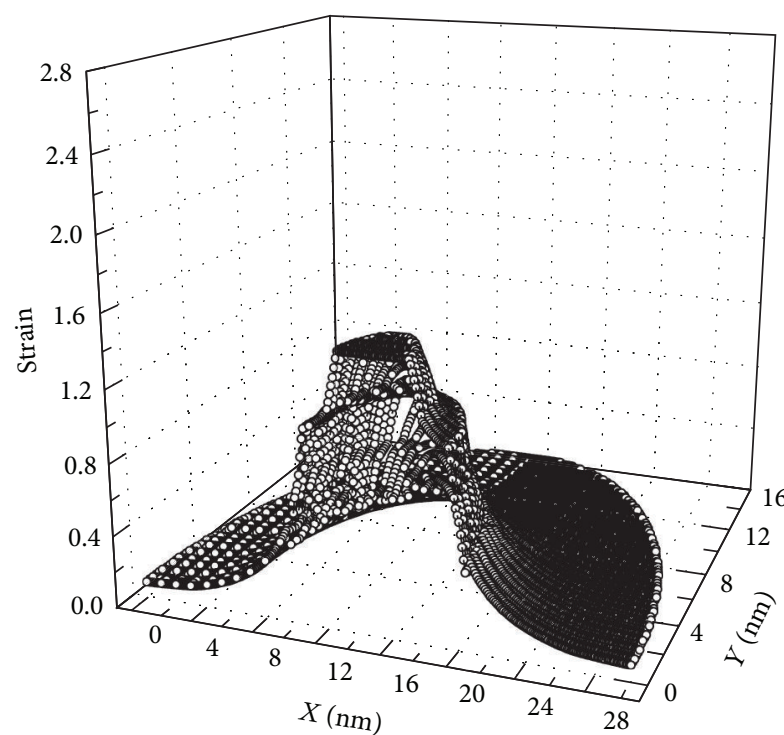

(a)

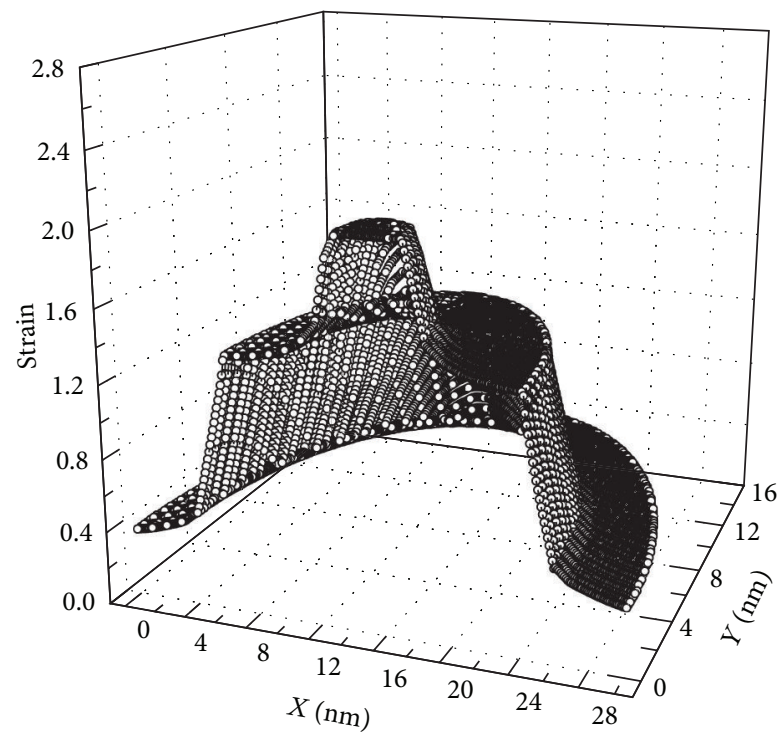

(c)

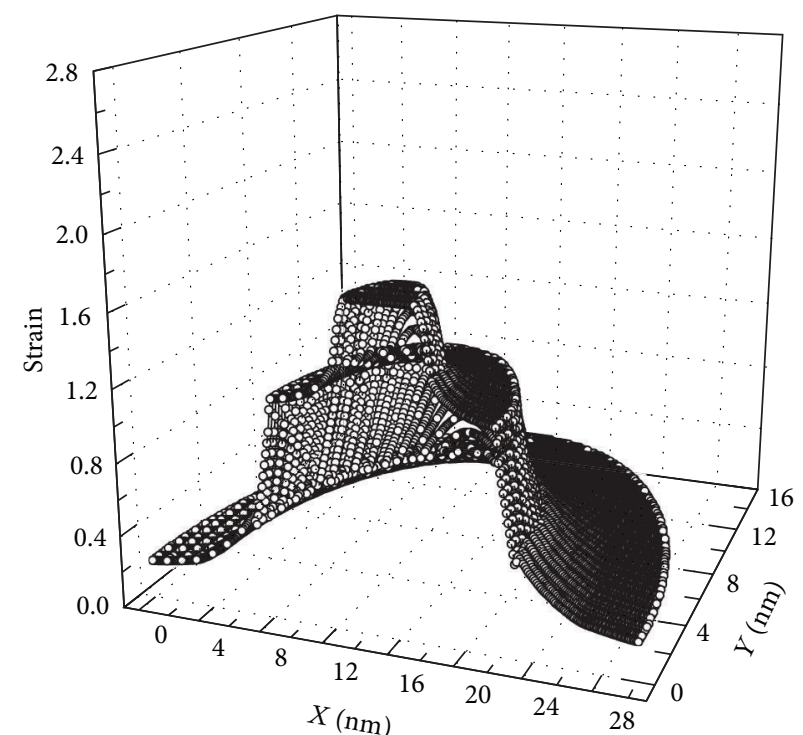

(b)

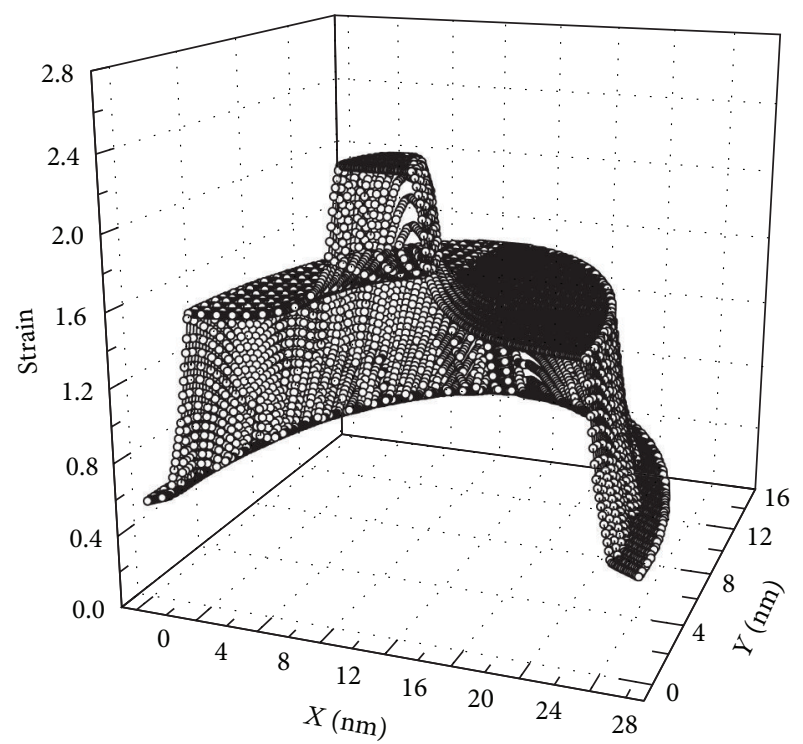

(d)

Figure 4: $X-Y$ plane strain profiles of $\mathrm{Ag} / \mathrm{Au}$ nanoparticles with the shell thickness of (a) $2.5 \mathrm{~nm}$, (b) $5 \mathrm{~nm}$, (c) $7.5 \mathrm{~nm}$, and (d) $10 \mathrm{~nm}$, respectively.

plays an important role in tuning the surface states and surface plasmon resonance of $\mathrm{Au} / \mathrm{Ag}$ and $\mathrm{Ag} / \mathrm{Au}$ nanoparticles.

\section{Conclusion}

In summary, the shell thickness-dependent strain distributions of the $\mathrm{Au} / \mathrm{Ag}$ and $\mathrm{Ag} / \mathrm{Au}$ core-shell nanoparticles embedded in $\mathrm{Al}_{2} \mathrm{O}_{3}$ matrix have been investigated by FEM calculations, respectively. The simulation results clearly indicate that there is a substantial strain applied on both the $\mathrm{Au} / \mathrm{Ag}$ and $\mathrm{Ag} / \mathrm{Au}$ core-shell nanoparticles by the $\mathrm{Al}_{2} \mathrm{O}_{3}$ matrix, and the strain distributes homogeneously in the core and inhomogeneously in the shell. For the Au/Ag nanoparticle, the strain reaches the maximum at the interface and is weaker in the core than that in the shell. For the $\mathrm{Ag} / \mathrm{Au}$ nanoparticles, the strain decreases monotonously from the core to the shell. For these two nanoparticles with the same shell thickness, the strain in the core is larger for $\mathrm{Ag} / \mathrm{Au}$ than that for $\mathrm{Au} / \mathrm{Ag}$ nanoparticles. With the shell thickness increasing, both of the strains in $\mathrm{Au} / \mathrm{Ag}$ and $\mathrm{Ag} / \mathrm{Au}$ nanoparticles are enhanced, and the strain gradient in the shell decreases gradually. These results demonstrate an effective method to manipulate the strain distributions of the $\mathrm{Au} / \mathrm{Ag}$ and $\mathrm{Ag} / \mathrm{Au}$ nanoparticles by tuning the thickness of the shell, which plays an important role in optical properties of $\mathrm{Au} / \mathrm{Ag}$ and $\mathrm{Ag} / \mathrm{Au}$ nanoparticles. 


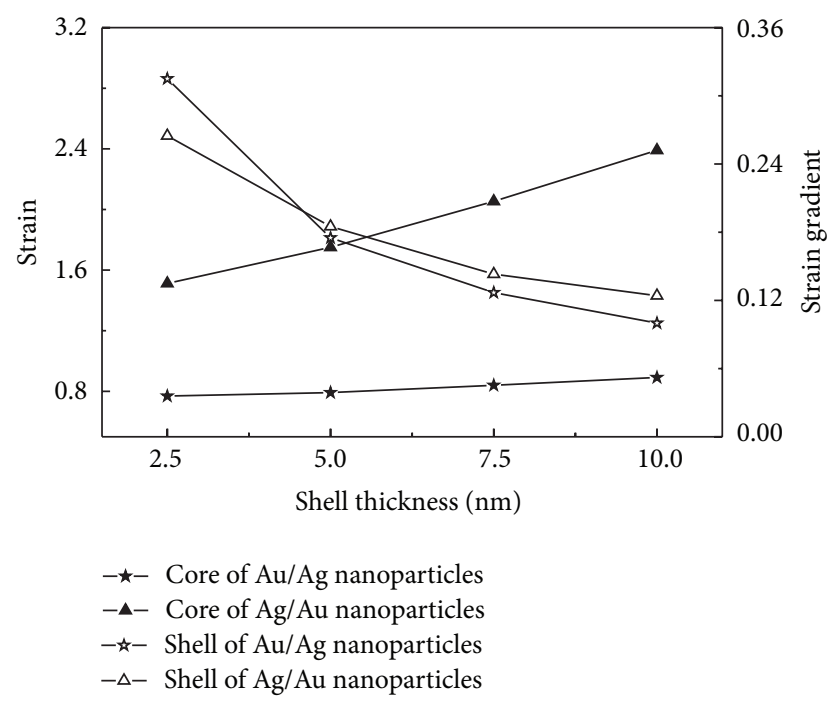

FIGURE 5: Strain on the core, strain gradient in the shell of the $\mathrm{Au} / \mathrm{Ag}$ and $\mathrm{Ag} / \mathrm{Au}$ nanoparticles with the shell thickness of $2.5 \mathrm{~nm}, 5 \mathrm{~nm}$, $7.5 \mathrm{~nm}$, and $10 \mathrm{~nm}$, respectively.

\section{Conflict of Interests}

The authors declare that there is no conflict of interests regarding the publication of this paper.

\section{Acknowledgment}

This work is supported by National Natural Science Foundation of China (Grant nos. 11164008, 51461019, 11174226, and 51371129).

\section{References}

[1] B. Wiley, Y. Sun, and Y. Xia, "Synthesis of silver nanostructures with controlled shapes and properties," Accounts of Chemical Research, vol. 40, no. 10, pp. 1067-1076, 2007.

[2] L. Lu, A. Kobayashi, K. Tawa, and Y. Ozaki, "Silver nanoplates with special shapes: controlled synthesis and their surface plasmon resonance and surface-enhanced Raman scattering properties," Chemistry of Materials, vol. 18, no. 20, pp. 48944901, 2006.

[3] Y.-S. Shon and E. Cutler, "Aqueous synthesis of alkanethiolateprotected Ag nanoparticles using bunte salts," Langmuir, vol. 20, no. 16, pp. 6626-6630, 2004.

[4] Z. S. Pillai and P. V. Kamat, "What factors control the size and shape of silver nanoparticles in the citrate ion reduction method?" The Journal of Physical Chemistry B, vol. 108, no. 3, pp. 945-951, 2004.

[5] J. H. Hodak, A. Henglein, M. Giersig, and G. V. Hartland, "Laser-induced inter-diffusion in AuAg core-shell nanoparticles," The Journal of Physical Chemistry B, vol. 104, no. 49, pp. 11708$11718,2000$.

[6] I. Srnová-Šloufová, F. Lednický, A. Gemperle, and J. Gemperlová, "Core-shell (Ag)Au bimetallic nanoparticles: analysis of transmission electron microscopy images," Langmuir, vol. 16, no. 25, pp. 9928-9935, 2000.
[7] C. C. Li, L. Sun, Y. Q. Sun, and T. Teranishi, "One-pot controllable synthesis of au@ag heterogeneous nanorods with highly tunable plasmonic absorption," Chemistry of Materials, vol. 25, no. 13, pp. 2580-2590, 2013.

[8] L. H. Lu, G. Y. Sun, H. J. Zhang et al., "Fabrication of core-shell $\mathrm{Au}-\mathrm{Pt}$ nanoparticle film and its potential application as catalysis and SERS substrate," Journal of Materials Chemistry, vol. 14, no. 6, pp. 1005-1009, 2004.

[9] F. Hubenthal, N. Borg, and F. Träger, "Optical properties and ultrafast electron dynamics in gold-silver alloy and core-shell nanoparticles," Applied Physics B: Lasers and Optics, vol. 93, no. 1, pp. 39-45, 2008.

[10] J. Schmitt, P. Mächtle, D. Eck, H. Möhwald, and C. A. Helm, "Preparation and optical properties of colloidal gold monolayers," Langmuir, vol. 15, no. 9, pp. 3256-3266, 1999.

[11] U. Kreibig and M. Vollmer, Optical Properties of Metal Clusters, Springer, Berlin, Germany, 1995.

[12] P. Mulvaney, "Surface plasmon spectroscopy of nanosized metal particles," Langmuir, vol. 12, no. 3, pp. 788-800, 1996.

[13] A. K. Samal, L. Polavarapu, S. Rodal-Cedeira, L. M. LizMarzán, J. Pérez-Juste, and I. Pastoriza-Santos, "Size tunable Au@Ag core-shell nanoparticles: synthesis and surface-enhanced raman scattering properties," Langmuir, vol. 29, no. 48, pp. 15076-15082, 2013.

[14] O. Peña-Rodríguez and U. Pal, “Au@Ag core-shell nanoparticles: efficient all-plasmonic Fano-resonance generators," Nanoscale, vol. 3, no. 9, pp. 3609-3612, 2011.

[15] J. B. Lassiter, H. Sobhani, J. A. Fan et al., "Fano resonances in plasmonic nanoclusters: geometrical and chemical tunability," Nano Letters, vol. 10, no. 8, pp. 3184-3189, 2010.

[16] J. A. Fan, C. Wu, K. Bao et al., "Self-assembled plasmonic nanoparticle clusters," Science, vol. 328, no. 5982, pp. 1135-1138, 2010.

[17] N. Liu, T. Weiss, M. Mesch et al., "Planar metamaterial analogue of electromagnetically induced transparency for plasmonic sensing," Nano Letters, vol. 10, no. 4, pp. 1103-1107, 2010.

[18] S. Mukherjee, H. Sobhani, J. B. Lassiter, R. Bardhan, P. Nordlander, and N. J. Halas, "Fanoshells: nanoparticles with builtin Fano resonances," Nano Letters, vol. 10, no. 7, pp. 2694-2701, 2010.

[19] D. Gammon, "Quantum dots: strain is a problem no more," Nature Nanotechnology, vol. 7, no. 10, pp. 621-622, 2012.

[20] P. J. Simmonds, C. D. Yerino, M. Sun et al., "Tuning quantum dot luminescence below the bulk band gap using tensile strain," ACS Nano, vol. 7, no. 6, pp. 5017-5023, 2013.

[21] A. Wellner, V. Paillard, C. Bonafos et al., "Stress measurements of germanium nanocrystals embedded in silicon oxide," Journal of Applied Physics, vol. 94, no. 9, pp. 5639-5642, 2003.

[22] A. Cheung, G. de M. Azevedo, C. J. Glover et al., "Structural perturbations within Ge nanocrystals in silica," Applied Physics Letters, vol. 84, no. 2, article 278, 2004.

[23] H. G. Chew, F. Zheng, W. K. Choi, W. K. Chim, Y. L. Foo, and E. A. Fitzgerald, "Influence of reductant and germanium concentration on the growth and stress development of germanium nanocrystals in silicon oxide matrix," Nanotechnology, vol. 18, no. 6, Article ID 065302, 2007.

[24] T. Benabbas, Y. Androussi, and A. Lefebvre, "A finite-element study of strain fields in vertically aligned InAs islands in GaAs," Journal of Applied Physics, vol. 86, no. 4, pp. 1945-1950, 1999.

[25] Q. X. Pei, C. Lu, and Y. Y. Wang, "Effect of elastic anisotropy on the elastic fields and vertical alignment of quantum dots," Journal of Applied Physics, vol. 93, no. 3, pp. 1487-1492, 2003. 
[26] C. Yuan, Q. Liu, and B. Xu, "Strain-induced structural phase transition of Si nanoparticles," The Journal of Physical Chemistry C, vol. 115, no. 33, pp. 16374-16377, 2011.

[27] C. L. Yuan, B. Xu, and W. Lei, "Strain-induced direct band gap $\mathrm{LaAlO}_{3}$ nanocrystals," Materials Letters, vol. 68, no. 1, pp. 392394, 2012.

[28] C. L. Yuan, H. Cai, P. S. Lee, J. Guo, and J. He, "Tuning photoluminescence of $\mathrm{Ge} / \mathrm{GeO}_{2}$ core/shell nanoparticles by strain," Journal of Physical Chemistry C, vol. 113, no. 46, pp. 19863-19866, 2009.

[29] H. Huebner, D. L. Dewhirst, D. E. Smith et al., The Finite Element Method for Engineers, John Wiley \& Sons, New York, NY, USA, 2001.

[30] C. L. Johnson, E. Snoeck, M. Ezcurdia et al., "Effects of elastic anisotropy on strain distributions in decahedral gold nanoparticles," Nature Materials, vol. 7, no. 2, pp. 120-124, 2008.

[31] Z. W. Shan, G. Adesso, A. Cabot et al., "Ultrahigh stress and strain in hierarchically structured hollow nanoparticles," Nature Materials, vol. 7, no. 12, pp. 947-952, 2008.

[32] J. Grönqvist, N. Søndergaard, F. Boxberg, T. Guhr, S. Åberg, and H. Q. Xu, "Strain in semiconductor core-shell nanowires," Journal of Applied Physics, vol. 106, no. 5, Article ID 053508, 2009.

[33] D. Barettin, S. Madsen, B. Lassen, and M. Willatzen, "Comparison of wurtzite atomistic and piezoelectric continuum strain models: implications for the electronic band structure," Superlattices and Microstructures, vol. 47, no. 1, pp. 134-138, 2010. 

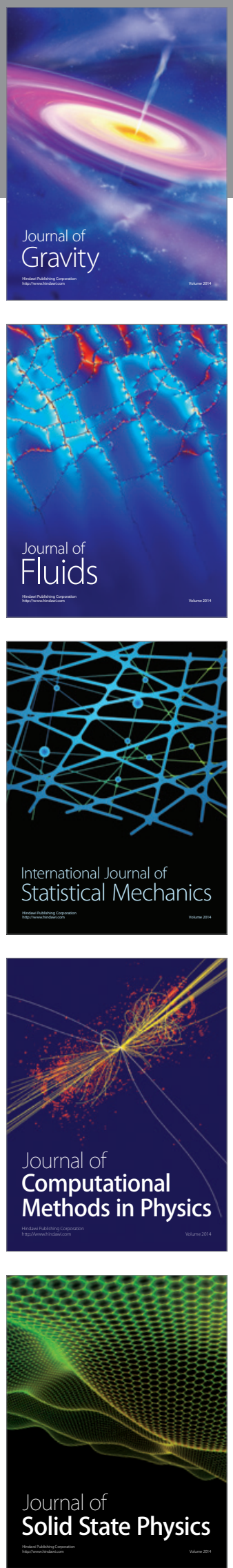

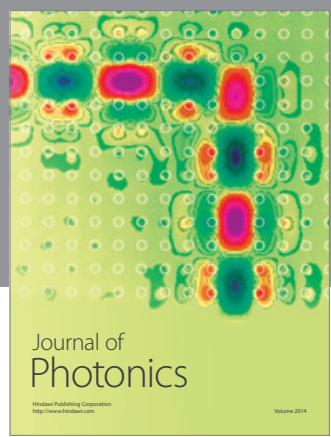

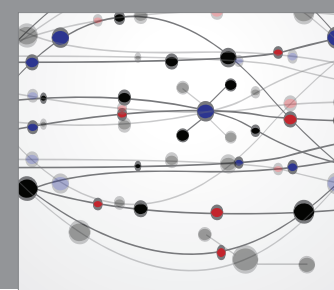

The Scientific World Journal

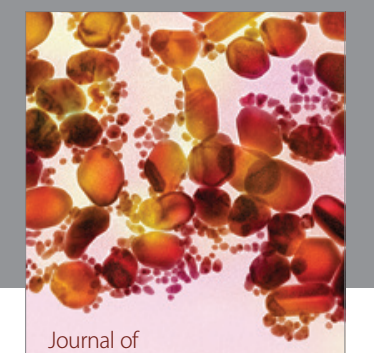

Soft Matter
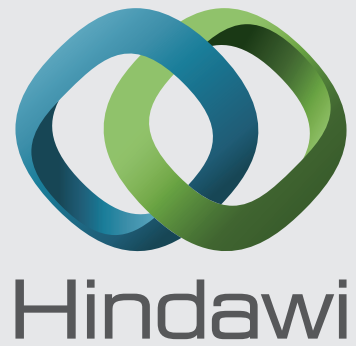

Submit your manuscripts at

http://www.hindawi.com
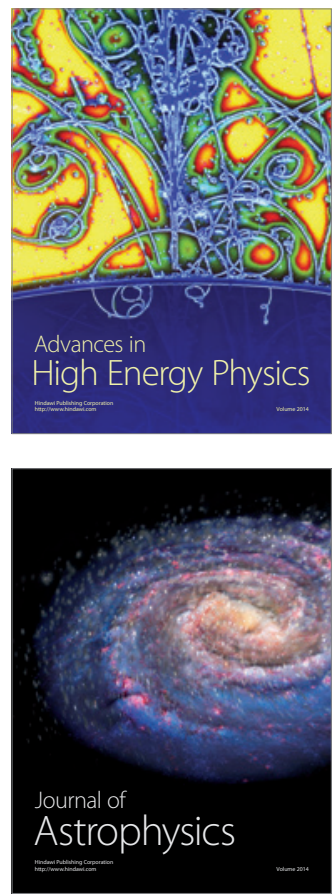
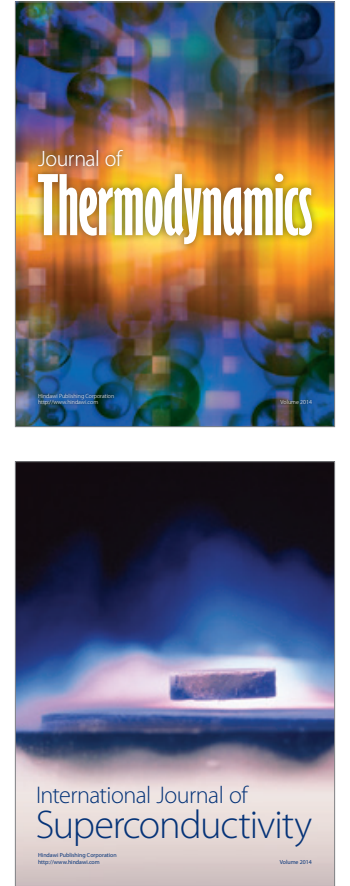
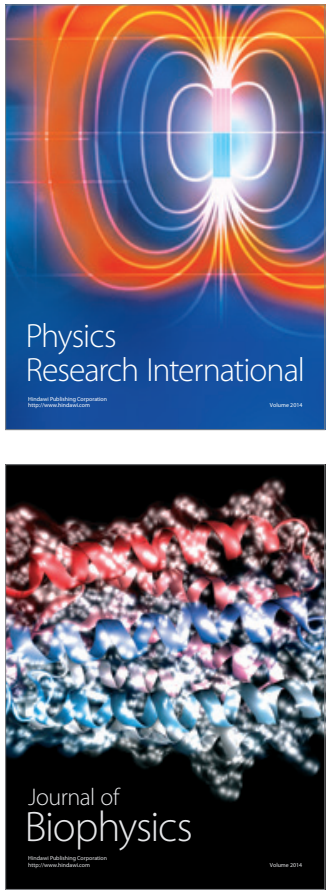
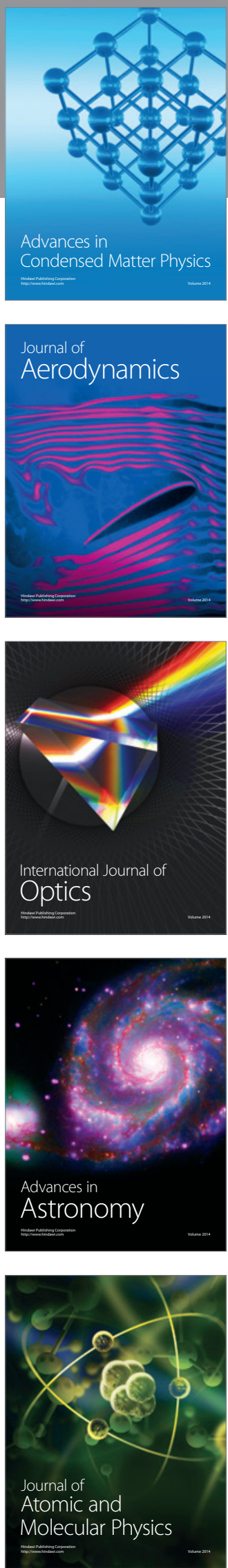